\title{
The Concentration and Competition of Vietnam Mobile Telecommunications Market Through HHI and Elasticity of Demand
}

\author{
Dang Thi Viet Duc ${ }^{1, *}$, Nguyen Phu Hung ${ }^{2}$ \\ ${ }^{1}$ Posts and Telecommunications Institute of Technology, Km 10 Nguyen Trai, Hanoi, Vietnam \\ ${ }^{2}$ VNU International School, Building G7-G8, 144 Xuan Thuy, Cau Giay, Hanoi, Vietnam
}

Received 16 April 2017

Revised 11 June 2017, Accepted 28 June 2017

\begin{abstract}
The article uses the Hirschman-Herfindahl Index (HHI) and the Elasticity of Demand to evaluate the degree of concentration and competition of Vietnam's mobile telecommunications market. For the HHI calculation, the article uses revenue market share data. For estimation of price elasticity of demand, the article uses a regression model with aggregate data of the whole market. The estimation results show high HHI, suggesting high concentration of the Vietnam mobile market which can harm the competition in the market. The high estimated price elasticity of demand indicates that price is actually powerful tool of competition and it is likely difficult for a single company to raise the price in the market without facing a decrease in its services demand. This gives implications for regulatory bodies for regulation options applied in the market.
\end{abstract}

Keywords: Market concentration, Price elasticity of demand, Competition, Telecommunications market, Mobile telecommunications market.

\section{Introduction}

Telecommunications services market is one of the markets on which the competition regulatory bodies focus their attention. This is because of the amount of radio spectrum available is limited and the fixed and common costs associated with mobile network investments are relatively high which make mobile telecommunications markets have been argued to be natural oligopolies [1]. Normally in competition regulation, the regulatory bodies should evaluate the degree of market competition and firm's market power to determine if economic regulation is necessary

\footnotetext{
${ }^{*}$ Corresponding author. Tel.: 84-914932612.

Email: ducdtv@ptit.edu.vn

https://doi.org/10.25073/2588-1116/vnupam.4087
}

and if so what the appropriate form of regulations is.

Many studies put effort to find out the methods to evaluate the degree of market competition in the telecommunications sector. Some overview studies include [2-5]. Although the studies are different in their focus, it may be possible to point out three sequential steps suggested by researchers to determine the degree of competition and non-competitive behavior of firms in the telecommunications market. Step 1: Define the market. Markets are defined along both product and geographic boundaries. This step is usually related to service cross-substitution tests such as SSNIP test, but other methods can be used as well [4]. Step 2: Assess the degree of market concentration to determine whether the market 
dominance exists and the ability of firms with market power to conduct non-competitive behavior in the market. This step can be done through analyzing some indices of market concentration or price elasticity of demand. Step 3: If the outcome of step 2 confirms suspicion of a firm or some firms having significant market power, the regulator should check that the firms are actually abusing the market power whether through analysis of surplus profit, economies of scale or barriers to entry and exit. This is a decisive step because the existence of a dominant market power is not as important as the fact that the business is actually abusing its power to stifle competition in the market. This paper focuses on analyzing and evaluating market concentration and the existence of significant market power in step 2.

In Vietnam, the telecommunications market dominant position is assessed on revenue and subscription market shares. Competition Law in 2004 and Telecommunications Law in 2009 agreed to take a benchmark of $30 \%$ market share to determine the market power and market dominant position of the firm(s) in a particular market. Taking the $30 \%$ market share as a threshold for the application of the prohibition provisions of Vietnam's Competition Law is explained that this benchmark is applied by many countries around the world. However, many studies have shown this to be the raw determinant of market dominant position in the telecommunications market [6].

The objective of this paper is to use internationally popular assessment methods to analyze market concentration and the existence of significant market power in the Vietnam's mobile services market. This study, on the one hand, is practically an important reference for Vietnamese telecoms regulators, competition regulators as well as firms participating in the market. On the other hand, this study also adds to the empirical literature on the topic for comparative studies.

This paper proceeds as follows. Section 2 is a brief review of empirical studies on market concentration and market competition. Section 3 presents an overview of the Vietnam's mobile market as a basis for the analysis of sections 4 and 5. Section 4 includes the calculation results of the Hirschman-Herfindahl index (HHI) and the estimated model of price elasticity of demand in Vietnam mobile services market which are comparable to other relevant studies. Section 5 gives some discussion of the results obtained before a conclusion is given in the last section.

\section{A brief review of literature}

In economics, market concentration is a function of the number of firms and their respective shares of the total production or sales in a market. It measures the extent of domination of production or sales by one or more firms in a particular market and is often used as a measure of competition. To evaluate market concentration and the existence of market dominating companies, researchers and regulatory bodies often derive from market shares. Enterprises with large market shares are more likely to control the prices and volumes of services provided in the market and thus gain higher returns. However, the market share only provides discrete information of each firm, so some aggregate indicators such as the C4 (4 firm concentration ratio) and HirschmanHerfindahl (HHI) indices have been released.

Market concentration indexes suggest if a particular market is being constituted by large firms or small businesses. The $\mathrm{C} 4$ index counts the market share of the four largest firms in the market. C4 above $80 \%$ indicates that the market is highly concentrated. The downside of the $\mathrm{C} 4$ and the like indices is that only a small number of the largest firms in the market are taken into account. That is the high $\mathrm{C} 4$ index can be because of two very large enterprises, or many small businesses competing in the market.

The Hirschman-Herfindahl index (HHI) is more widely used than $\mathrm{C} 4$ index to evaluate the market concentration. Cowling and Waterson 
[7] demonstrates that the HHI associated with the profitability of the firm represents the level of competition in the market. HHI is the sum of the squares of the market shares of enterprises in a market. If the HHI is at 10,000 , the market is monopolistic (only one enterprise). Low HHI value indicates that the market is highly competitive. High HHI value indicates the low level of competition and high level of monopoly in the market. The value of HHI below 1,000 deems there to be no significant market power in a given market [3].

Due to its usefulness and simplicity, HHI is calculated in many studies of competition. The US Department of Justice has used the HHI in antitrust investigations in cases of merger consolidation [4]. [8] uses HHI to investigate the concentration level of India mobile market and concludes that the market is highly fragmented where many operators are under $10 \%$ subscriber market share. [9] indicates high HHI of Ghana telecommunications market suggesting that the market is highly concentrated and not competitive. [10] examines by an empirical study the relationship between HHI and earning of dominant players in the telecommunications markets of Middle East and Africa countries. [11] provides an revision- an interval estimate- for HHI when the knowledge about the market is incomplete. Actually, these indicators are useful, but researchers and policymakers still cannot determine exactly at which benchmark of HHI the market is supposed to be effectively competitive [3, 12].

$[1,13]$ and [14] and many other studies estimate the price elasticity of demand and supply to evaluate market competition and examine whether the largest enterprises are able to unilaterally increase prices in the market while still maintain the demand for some services. Price elasticity of demand reflects the responsiveness, or elasticity, of the quantity demanded of a good or service to a change in its price. If the demand curve is less elastic, service consumers are unlikely to give up the service even though the prices may increase. This means that the business obviously has the market power. Hakim and Neaime [15] argues that if demand for telecommunications services is less elastic, firms have an incentive to collude on the market. However, the elasticity of demand indicates only the ability of the firm to conduct non-competitive behaviors; the actual abuse of the market power is not reflected clearly by the price elasticity of demand.

Empirical studies on demand elasticity require much of data. There are two different approaches of such studies. The first approach is based on secondary data either highly aggregate data on the whole market and/or firm-specific data. The second approach uses primary data through surveys of consumers' behavior. Hausman [16], for example, uses data from 30 markets in the United States between 1988 and 1993 and finds a price elasticity of mobile service access of -0.51 . The UK Competition Commission [17], summarizing the various research results, reports the price elasticity of demand for subscription ranging from -0.08 to -0.54 and price elasticity of demand for mobile originated call from -0.48 to -0.62. Grzybowski [18] applies structural models to study the competitive behavior of mobile operators with data from EU countries in the period of 1988-2002. Research results show the price elasticity of demand for mobile services between -0.2 and -0.9 .

Telecoms regulatory bodies use HHIs and price elasticity of demand to decide forms of regulation [4, 19]. TATT [19] specifies that price elasticity analysis is an essential step taken to identify market dominance in Trinidad and Tobago. Jamison et al. [4] studies three cases of telecoms competition in the US, UK and Japan. In the case of examining the level of competition in the long-distance telephone market where AT\&T dominated the market share, the FCC measured factors including (1) AT\&T's market share and market trend, (2) price elasticity of supply for services to determine competitor's service substitution for AT\&T's services, (3) price elasticity of demand, 
and (4) cost structure, the size and resources of AT\&T and its competitors. As a result, in 1993, the FCC decided that AT\&T was not a dominant player in the market, despite the fact that AT\&T's market share in the long-distance voice market in 1994 was still $55.2 \%$ in revenue and $58.6 \%$ in call traffic. The telecommunication regulatory body of UK, Ofcom, also used market share, price elasticity of supply and demand to conclude that Vodafone, O2, Orange, T-Mobile and H3G are players with significant market power in the mobile call termination market. Then Ofcom took some control of the price of mobile termination services from April 1, 2007 to April $1,2011$.

However, there are some complexities involved in the estimation and use of the information of price elasticity of demand. These include the change of price elasticities as the prices themselves change, the difference of long-run and short-run elasticities of demand for goods and services of which consumers display some inertia, the problems associated with estimation of demand curves where market equilibria in supply and demand are observed points. (see [20]). All these complexities are evidently relevant to the market for telecommunications services.

\section{The state of mobile telephone market in Vietnam}

Vietnam's first mobile network, Mobifone, was established in 1993 by Vietnam Posts and Telecommunications (VNPT) group in association with Comvil Vietnam AB of Kennevik Group, Sweden. In 1996, VNPT established the second mobile network, Vinaphone. There was nearly no competition in the mobile telecommunications market since both Mobifone and Vinaphone were owned or partially own by VNPT. In 2004, Viettel- a network of the Military Telecom Corporation, was born and developed strongly which made a landmark change in the mobile services market in Vietnam. In 2014, Mobifone was officially separated from VNPT to be an independent network. Market competition intensifies.

Figure 1 shows changes in subscription market shares of operators in Vietnam mobile telecommunications market in the last decate. Viettel with competitive services charges, attractive promotion packages and good aftersale services have successed passing Vinaphone and Mobifone to be the largest operator in the market. In 2006, Viettel's market share was $23 \%$ which increased to about $50 \%$ in 2016 . The market share of Mobifone shrank from $36.5 \%$ to $27.3 \%$ after 11 years, while that of Vinaphone also decreased from $35 \%$ to $16.2 \%$ in the same period. From 2009 to 2014, both Viettel and VNPT were considered the dominant players in the mobile services market since either the separate market share is over $30 \%$ or the joint market share is over $50 \%$. After Mobifone's separation from VNPT in 2014, Viettel is the only dominant firm in the market and must comply with separate regulations.

Another noted feature of Vietnam mobile services market competition is that the share of small operators also increases in some years, but eventually decreases. In 2016, there are only two small operators left with faint activities. Up to now, Vietnam's mobile market has set a relatively firm competition situation with three big operators.

The drastical competition in the mobile services market leads to substantial decrease of service prices, more attractive promotions, more value added services with better quality, all resulting in a continuous increase in mobile subscription. Figure 2 shows the reduction of mobile service charges and the growth mobile service revenues in Vietnam. However, with the continue growth of Viettel, some worries are renewed about the concentration and competition of the market. 


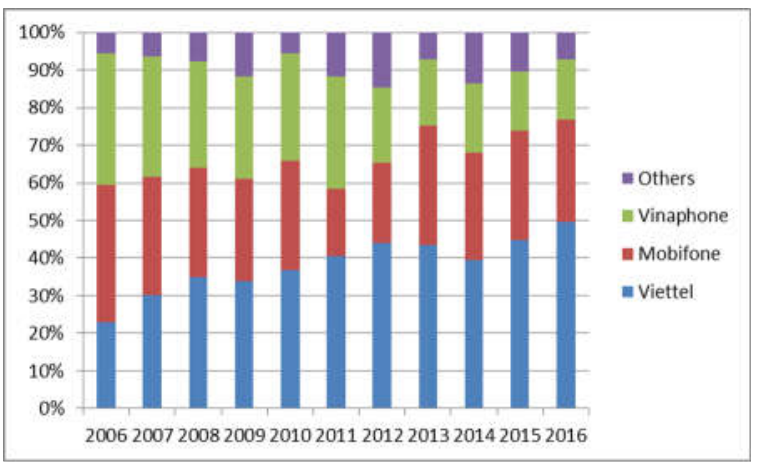

Figure 1. Subscription market share of mobile service operators in Vietnam. (Source: Data from [21, 22])

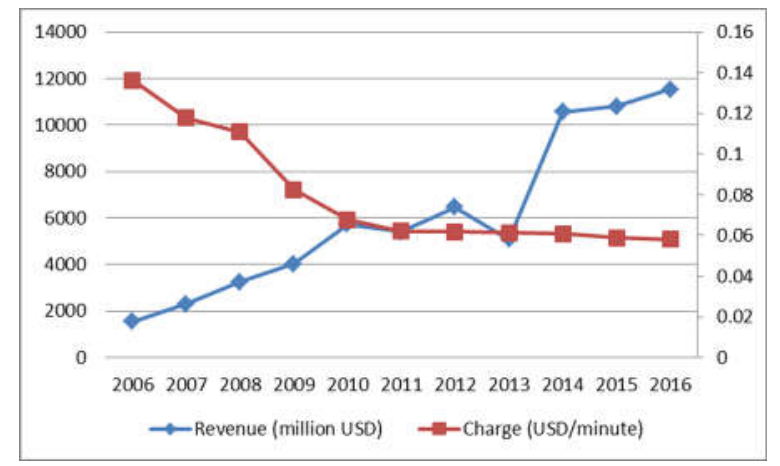

Figure 2. Total revenue and average charges of mobile services in Vietnam. (Source: Data from [21, 22])

\section{Methodology and data}

The article uses the above indicated typical methods to evaluate the market concentration of Vietnamese mobile services in order to make a comparative analysis between Vietnam market with some other mobile markets in different countries.

To calculate the market concentration index HHI , we can use the market share of mobile networks by subscription and by revenue. Due to the discontinuity of mobile operator revenue data over the years, this article uses subscription market share from [21] to calculate HHI. In HHI calculation, although Mobifone and Vinaphone are two different networks, before 2014, these two networks are either owned or controlled by VNPT, so the market share of the two networks is merged between 2006 and 2013. In 2015 and 2016 the market share of these two networks is calculated separately.

For estimation of price elasticity of demand, the most commonly used model is in linear logarithms form (see $[1,15])$ :

$$
\ln D_{t}=\alpha_{t}+\beta_{1} \ln P_{t}+\sum_{k=2}^{K} \beta_{k} \ln X_{t, k}+\varepsilon_{t}
$$

Where $D_{t}$ is the service demand at time t, $P_{t}$ is the service price at time $\mathrm{t}, X_{t, k}$ are the factors explaining the demand out of the price, such as per capita income, total number of subscription over time.

The service demand is defined as the number of minutes of mobile calls, measured by taking mobile service revenue divided by average price. Revenue includes sales of various types of mobile services such as SMS, on-net, off-net, mobile generated calls as well as mobile termination services. The average price is constructed by taking the weighted average of the net prices, on-net and off-net, peak and low, and market share of network operators. Per capita income and Total subscription are used as explanatory variables with the assumption that as the income increases, demand for mobile telecommunications services increases; as the total number of subscription increases (due to non-price reasons), the demand for mobile telecommunications services increases. When estimating elasticity of demand model for the telecommunications market, it should be noted that prices and demands are not determined concurrently because markets are not perfectly competitive. Rates are usually determined in advance through the management of government agencies, after which demand will change accordingly, so the endogeneity problem may not be as noticeable as in the models estimated for other non-telecoms market.

Data is collected from the statistics books on Information and Communication Technologies [21] and reports of the Vietnam Ministry of Information and Communication, 
the Vietnam General Statistics Organization and the websites of service providers. The data is verified to ensure the consistence among different sources of data. Due to lack of data, the study only estimates the aggregate market model with data for 11 years, from 2006 to 2016. In principle, to examine the ability of firm to change the market price (i.e. significant market power) the study needs to estimate the demand curve for each major firms doing business in the market.

For model estimation, the least squares (OLS) method is used to examine the significance of the variables introduced and the two-stage leastsquares model (TSLS) is applied to correct the possible endogeneity problem. The resulting model together with the test values is shown in Table 2. Apart from price, statistically significant explanatory variable is Per-capita Income. Parameters in the model are consistent with theoretical predictions and statistically significant (T-tests). The F test for model simultaneous significance of variables and R2 parameters support the result model.

\section{Results and discussion}

Table 1 shows the concentration index HHI of Vietnam. There is a declining trend of the level of concentration of the Vietnam's mobile telecommunications market in period of 20062015, which suggests that the market is more and more competitive. In 2016, however, with the continued strong development of Viettel, the HHI index rebounds.

The HHI of Vietnam compared with some countries in the world is summarized in Figure 3. Naldi and Flamini [11] provides some HHI benchmarks to state about the level of market concentration. If $\mathrm{HHI}$ is in the range of 1,5002,500 the market is considered moderate competitive. If $\mathrm{HHI}$ is over 2,500 the market is called highly concentrated. The US Department of Justice used the mark calculated of 1,800 in adjudicating competition disputes in the longdistance call telecommunications market [4]. As shown in figure 3, the HHI of the Vietnam's mobile market is still high compared to the benchmark of 2,500 and to the indices of many countries' mobile services markets. Moreover, the HHI tends to increase from 2016 forward. As such, Vietnam's mobile market is one of the highly concentrated ones which can reflect unfair competition among network operators, especially low opportunities for firms who would want to enter the market. This may be a sign that regulators need to consider.

Table 2 provide estimated model of demand curve of Vietnam mobile services. As pointed out in section 2, the elasticity of the demand for mobile telecommunications market estimated in the majority of studies ranges from 0.2 to 0.9 . Some special cases, for example, Malaysia's mobile access market are highly elastic, from 4.08 to -6.41 depending on the operator [23]. With $\beta=-1.4784$, the elasticity of demand determined in the mobile market in Vietnam is relatively high, i.e. the demand curve is elastic to price change; a small increase in mobile charges causes significant decrease in the service demand. This suggests that it would be difficult for a single firm to increase price while retaining its demand to earn high profit.

Table 1. HHI of Vietnam mobile services market

\begin{tabular}{llllllllllll}
\hline Year & 2006 & 2007 & 2008 & 2009 & 2010 & 2011 & 2012 & 2013 & 2014 & 2015 & 2016 \\
\hline HHI & 5649 & 4949 & 4545 & 4141 & 4704 & 4012 & 3775 & 4341 & - & 3161 & 3484 \\
\hline
\end{tabular}

(Source: Data from [21, 22], and authors' calculation) 


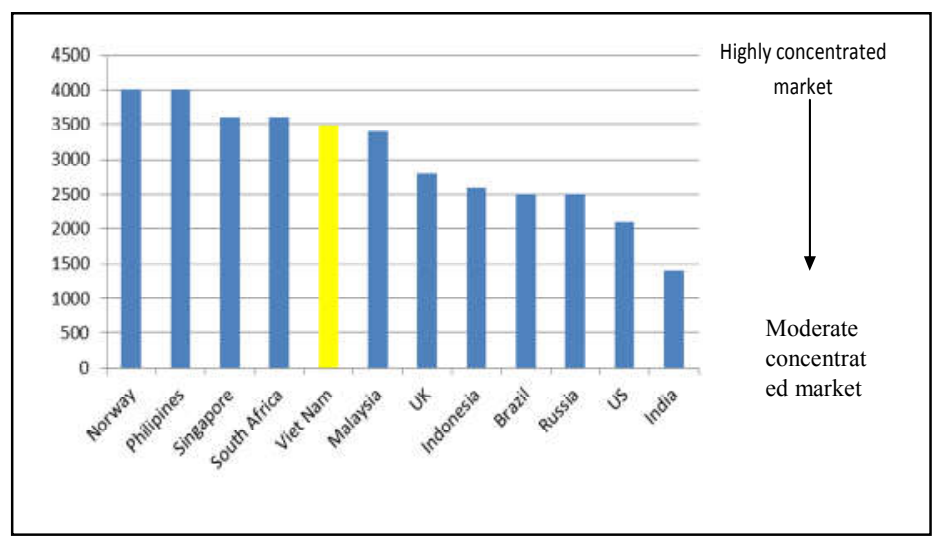

Figure 3. Herfindahl-Hirschman Index of Vietnam's and some other countries' mobile services markets. (Source: Data from [8] and authors' calculation)

Table 2. Estimated model of price elasticity of demand for Vietnam mobile servicesr

\begin{tabular}{|c|c|c|c|c|}
\hline \multicolumn{5}{|c|}{ Coefficients: } \\
\hline & Estimate & Std. Error & $\mathrm{t}$ value & $\operatorname{Pr}(>|t|)$ \\
\hline (Intercept) & 7.6463 & 5.7069 & 1.340 & 0.217107 \\
\hline $\log (\mathrm{P})$ & -1.4784 & 0.5454 & -2.711 & $0.026636 *$ \\
\hline $\log (\mathrm{I})$ & 1.3957 & 0.2088 & 6.684 & $0.000155 * * *$ \\
\hline Signif. cod & es: 0 ‘***’ & 0.001 ' $* *$, & 0.01 '*' & $0.05^{\prime}, \quad 0.1{ }^{\prime}, 1$ \\
\hline
\end{tabular}

Residual standard error: 0.2129 on 8 degrees of freedom ( 1 observation deleted due to missingness)

Multiple R-squared: 0.9593, Adjusted R-squared: 0.9492

F-statistic: 94.38 on 2 and 8 DF, p-value: $2.733 \mathrm{e}-06$

(Source: Data from [21, 22] and authors' model estimation)

The results of the computation, comparison of the HHI and the price elasticity of demand show different implications of competition in the Vietnam mobile market. The HHI indicates that the concentration of the Vietnam mobile market is high compared with those of other countries. This suggests high extent of domination of sales by one or more firms in the mobile services market, in the case of Vietnam, Viettel's market share is about 50\%, which may harm the competition. The higher the HHI, the higher the profitability of the dominant market players is. According to consultancy firm McKinsey \& Company's study on the relationship between market share and margins achieved in Middle East and Africa, if $\mathrm{HHI}$ is in the range of 3,000-3,500, the market leader can have Earnings before interest, taxes and depreciation (EBITDA) reaching 47\%; the second and third companies are able to achieve a profit margin of $35 \%$ and $25 \%$, respectively [22]. Profit margins are generated by two sources: the size of sales and the effectiveness of the business. Thus, basically market-leading firms are having advantages and the opportunities for small firms, or new entrants to enter the market will be small. In the case of Vietnam, in addition to the high $\mathrm{HHI}$, there is another characteristic that the $\mathrm{HHI}$ is likely to rebound after a period of continuous 
decline. This is something that regulators need to pay attention.

The estimation shows that the demand of Vietnam mobile telecommunications market has relatively more elastic demand than many other countries. For every one price unit drop, services volume increases by 1.47 units. This may be related to the characteristics of the low-income market when price are considered as the most important factor for the selection and consumption of services. Thus, price-based competition is important in Vietnam. This result also suggests that it is difficult for a firm to increase its price in the market without harming its demand of service. In contrast, price reduction can be a strategy of large firm to exclude the competitors as long as its profit margin remains positive. Therefore, price regulation in the direction of anti-predatory pricing is appropriate in Vietnam.

Due to the lack of business data, the article does not estimate the separate demand model for each mobile operator, including Viettel, Mobifone or Vinaphone, so it is not yet clear whether each of these large firms can definitely impact the market price, from that to determine their market power.

\section{Conclusion}

So far, in Vietnam, market share (by revenue and by subscription) is the only parameter that determines the dominant position of a market player and is the basis for any regulation form to be taken. However, the market share(s) of one or some large firms does not fully reflect the concentration of the market nor does it show how much power the firm can release to change market prices to earn surplus profit. This article uses common international indicators and measures to assess the level of market concentration and competition for Vietnam mobile telecommunications market. The two indicators calculated are the $\mathrm{HHI}$ and the elasticity of the demand, which allow a comparison of the competition position of the Vietnam mobile market against other countries. The two indicators also help the interpretation of the market characteristics as well as provide some implications about the price and demand trend in the mobile telecommunications market of Vietnam. These are also important indicators for regulators to refer to before introducing any specific regulation.

The article has certain limitations, mainly related to collected data. Firstly, when determining the HHI, the article bases on the subscription market share, but HHI should be calculated also based on the revenue market share which is the benefit indicator associated with the business. Second, the data of demand, price and other variables for price elasticity of demand estimation were collected from various sources (Ministry of Information and Communications, Vietnam Government Statistics Organization, ITU, business reports). Data from these sources sometimes are not consistent affecting the estimation results. The length of the time series date is also short. Third, research has not yet collected data to calculate the elasticity of demand for mobile telecommunications services of each network operator. This estimation would indicate the market power of each firm in the market, so that the picture of concentration and competition in the mobile telecommunications market will be clearer.

In the future, the article could overcome the disadvantages by either trying to collect firmspecific data from different competitors in the market, or through a different approach using primary data by survey to determine the demand function model of the market.

\section{References}

[1] J. Haucap, R., Dewenter, Estimating Demand Elasticities for Mobile Telecommunications in Austria, Discussion paper No. 33, Institute for Economic Policy, Helmut-Schmidt University, Germany, 2004.

[2] M. Boyer, The Measure and Regulation of Competition in Telecommunications Markets, 
CIRANO (Center Interuniversity of Research and Analysis Organization), 2005.

[3] J. Hauge, M. Jaminson, Analyzing Telecommunications Market Competition: Foundations for Best Practices, Public Utility Research Center, University of Florida, 29 October, 2009.

[4] M. Jamison, S. Berg, L. Jiang, Analyzing Telecommunications Market Competition: A Comparison of Cases, Public Utility Research Center, University of Florida, 4 November, 2009.

[5] Schwarz, Measuring the Intensity of Competition- Experiences from Austrian Broadband Markets, Intereconomics, 46 (2011) 1, pp. 27-35.

[6] Lưu Hương Ly, Evaluate the Market Power in Law of Competition of Vietnam (Đánh giá sức mạnh thị trường trong Luật cạnh tranh), Journal of Journal of Legislative Studies (Tạp chí nghiên cứu lập pháp), 2004, retrieved from http://vnclp.gov.vn/ct/cms/tintuc/Lists/ThucTien PhapLuat/View_Detail.aspx?ItemID $=84$ on 8 th June 2017.

[7] K., Cowling, M. Waterson, Price-cost Margins and Market Structure, Economica, 43 (1976) 171, pp. 267-274.

[8] J. Dharmapalan, Inside Telecommunications, EY report, 2016, retrieved from http://www.ey.com/Publication/vwLUAssets/EY_Inside Telecommunications -

- Issue_ $12 / \$$ FILE/EY-inside-telecommunicationsissue-12.pdf on 8th June 2017.

[9] A. S. George, A. Michael, K.A.P. Agyekum, The Ghanaian Telecommunications Market Concentration - Applying the US DOJ's HHI Criteria for Determining Market Power(s), Working Paper, Ohio University, March, 2016.

[10] D. Boniecki et al., 2016, Middle East and Africa Telecommunications Industry at Cliff's Edge: Time for Bold Decisions, McKinsey\&Company, 2016.

[11] M. Naldi, M. Flamini, Interval Estimation of the Herfindahl-Hirschman Index Under Incomplete Market Information, UK-Sim-AMSS 16th International Conference on Computer Modelling and Simulation, 2014, pp. 317-322.
[12] T. Robert , 2014, When bigger is Better: A Critique of the Herindahl-Hirschman Index's Use to Evaluate Mergers in Network Industries, Pace Law Review, 34(2), pp. 894-946.

[13] NCC (Nigerian Communications Commission), Determination of Dominance in Selected Communications Markets in Nigeria, 2014.

[14] R. Hawthorne, How Competitive are Markets for Telecommunications Services in South Africa, CCRED, University of Johannesburg, 2016.

[15] S. Hakim, S. Neaime, The Demand Elasticity of Mobile Telephones in the Middle East and North Africa, Research in International Business and Finance, 32 (2014), pp. 1-14.

[16] J. Hausman, Efficiency Effects on the U.S. Economy from Wireless Taxation, National Tax Journal, 53 (2000), pp. 733-744.

[17] UK Competition Commission, Vodafone, O2, Orange, T-Mobile, Report on References under section 13 of the Telecommunication Acts 1984 on the Charges made by Vodafone, O2, Orange and T-Mobile for Terminating Calls from Fixed and Mobile Networks, London, February, 2003.

[18] L. Grzybowski, The Competitiveness of Mobile Telecommunications Industry Across the European Union, Discussion Paper, Munich Graduate School of Economics, July 2004.

[19] TATT (Telecommunications Authority of Trinidad and Tobago), Price Regulation Framework for Telecommunications Services in Trinidad and Tobago, 2013.

[20] K. Dzieciolowski, J.W. Galbraith, Indicators of Wireline/Wireless Competition in the Market for Telecommunication Services, Project Report, CIRANO, 2004.

[21] MIC (Vietnam Ministry of Information and Communication of Vietnam), Information and Data on Information and Communication Technology, 2006- 2016.

[22] ITU (International Telecommunication Union), World Telecommunication/ICT Indicators database, 2016.

[23] R. Latimaha, Z. Bahari, Elasticity of Demand for Cellular Phone Network Access in Malaysia, Journal of Economy Malaysia, 50 (2016) 2, pp. 125-132. 